\title{
Outcome of urethrocutaneous fistula repair after hypospadias surgery

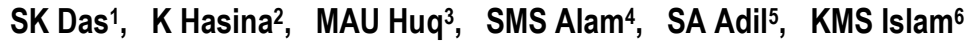

\begin{abstract}
Background: Urethrocutaneous fistula is the most prevalent complication after urethroplasty. Many methods have been developed for correction, and the best technique is determined based on the size, location, and number of fistulas, as well as the status of the surrounding skin.

Objective: To compare the outcome of local dartos flap and tunnelled tunica vaginalis coverage in cases of repair of urethrocutaneous fistula.

Materials and Methods: In the period of 2015-2018, 51 patients with 51 fistulas with an average age of 81.3 months (range 21-156 months) were classified into coronal-19, distal penile-11, mid penile-14, proximal penile-5 and penoscrotal-2. Thirty six patients were repaired with local dartos flap coverage and 15 patients were repaired with tunnelled tunica vaginalis coverage.

Results: The repair was successful in all patients of tunica vaginalis coverage but 7 patients of dartos flap coverage developed recurrent fistulas ( $p$ value 0.066). There was no patient of scrotal complications. There were no statistically significant differences regarding age $(p=0.83)$, location of fistula $(p=0.40)$, size of fistula ( $p=0.29)$.

Conclusions: Though the result of this study with such a small sample was not statistically significant, tunica vaginalis coverage seems to be better than dartos flap coverage in preventing recurrence.
\end{abstract}

Key words: Urethrocutaneous fistula, Dartos flap, Tunica vaginalis.

\section{Introduction}

Urethrocutaneous (UC) fistula is the commonest complication of hypospadias surgery. Different methods have been described for managing this frustrating complication. ${ }^{1,2}$ Availability of covering tissue for multilayer repair; the time interval after any interventions; the patient's age; number, location, and size of fistula; use of magnification; previous fistula repairs; tension free closure with suitable suture material; and the surgeon's skill are the major determinants of successful repairs. ${ }^{3,4}$ Some failure rate is expected in every type of available procedures of repair. Besides the use of local dartos tissue, tunica vaginalis is another tissue that can be used as a second layer for preventing recurrence in fistula repair. The aim of the study is to evaluate the role of local dartos tissue and tunnelled tunica vaginalis as second layer in multilayered closure of UC fistula.

\section{Materials and Methods}

It was a retrospective study conducted during the period of January 2015 to December 2018 in the Department of Pediatric Surgery, Dhaka Medical College and Hospital (DMCH), Dhaka on 51 boys who developed UC fistula after hypospadias surgery in the Snodgrass technique. Data was taken from the hospital records of all patients who underwent repair of UC fistula in the different techniques. Help was also taken from the yearly departmental audits of 2015 to 2018. They were classified into coronal-19, distal penile-11, mid penile-14, proximal penile-5 and penoscrotal-2. All the UC fistula was repaired at least 6 months after the hypospadias surgery. Patients with fistula size of $>6 \mathrm{~mm}$, recurrent fistula, multiple fistulas, fistula after circumcision, meatal stenosis, urethral stricture and diverticulum were excluded.

1. Sahadeb Kumar Das MS, Asstt. Prof., Dept. of Pediatric Surgery, Khuina Medical College Hospital. (E-mail: sahadebk8@yahoo.com)

2. Kaniz Hasina MS, Professor, Dept. of Pediatric Surgery, Dhaka Medical College, Dhaka.

3. Md Ashraf U1 Huq PhD, Professor and Head, Dept. of Pediatric Surgery, Dhaka Medical College, Dhaka.

4. S M Shafiqul Alam DA, Associate Professor, Dept. of Anaesthesiology and ICU, Dhaka Medical College, Dhaka.

5. Syed Abdul Adil MS, Resident Surgeon, Dept. of Pediatric Surgery, Dhaka Medical College Hospital, Dhaka. 


\section{Surgical technique-}

After general anaesthesia, patients were prepared and draped in supine position. Location of the fistula and exclusion of any additional fistula were confirmed by injecting normal saline under pressure into the terminal portion of neourethra with simultaneous pressure at the base of the penis. The size of the fistula was determined with calipers. A urethral stent (6 or $8 \mathrm{Fr}$ ) was passed. After making a circumferential incision around the fistula site, the fistulous tract was dissected upto the urethral mucosa. Then the tract was excised and urethral mucosa was repaired by interrupted sutures with $6 / 0$ Vicryl taking care to invert the urethral edges. The repair was covered with the layers of local vascularized dartos tissue mobilized from each side which were created as flaps and drawn across the repair in 36 patients.

In patients where tunica vaginalis flap given, one testicle was brought out through a separate scrotal incision. The scrotal attachments were carefully dissected. The tunica vaginalis was incised and reconfigured as a flap that was transferred to the repaired site through a subdartos tunnel. The distal edges of the tunica vaginalis were then sutured to the corporal tissue as to cover the suture line completely. The penile skin was closed with interrupted non overlapping sutures. After ensuring proper haemostasis, the respected testicle was replaced into the scrotum and fixed by suturing the rim of tunica vaginalis with dartos. Then the scrotal skin was closed with interrupted sutures. The transurethral stent was secured to the glans with the traction suture. Non compressive occlusive dressing was applied in all cases that was removed on 4th post operative day (POD). Wound was kept open and Mupirocin ointment was applied on the wound 3 times daily for 14 days. Stent was removed on 8 th POD and discharged on same day.

The outcome was assessed after removal of stent and after 2 weeks on first follow up. Statistical analysis was performed using the Statistical Package for Social Science (SPSS) version 25.0. P value $<0.05$ was considered to statistically significant.

\section{Results}

The characterization of the UC fistula is shown in Table I. The mean age of the patients is 81.3 months (range 21-156 months). The mean time interval between primary urethroplasty in the Snodgrass technique and the present attempt at fistula repair was approximately 10.45 months. The mean duration of the operation time in cases of dartos flap coverage was 97.67 minutes and in cases of tunica vaginalis coverage was 107.20 minutes.

Seven patients $(7 / 36)$ developed recurrent fistula at previous site in whom dartos flap was given as second layer coverage (success rate $80.5 \%$ ). No patient $(0 / 15)$ developed fistula in whom tunica vaginalis was given as second layer coverage (success rate $100 \%$ ). $\mathrm{P}$ value is 0.066 . To date, after a mean follow up of 19.9 months, there have been no further recurrences. There was no patient of scrotal complications. There were no

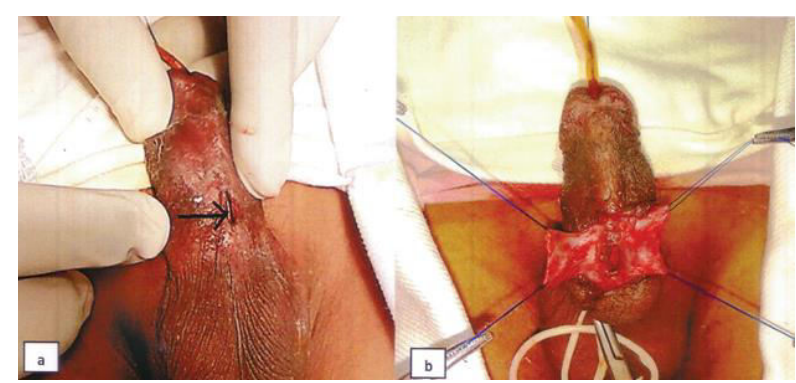

Figure 1. a) Fistula site before operation b) Mobilized dartos fascia on both sides

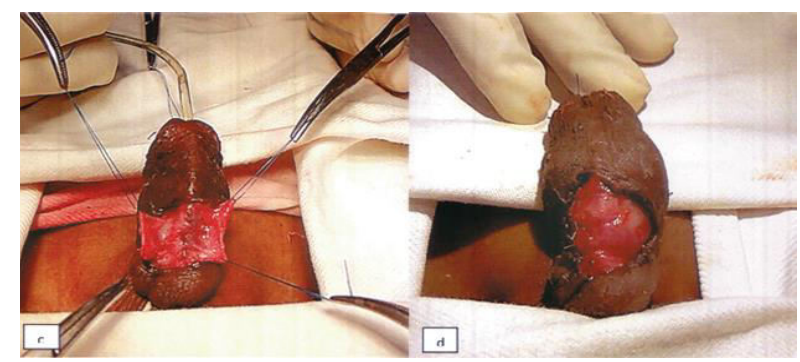

Figure 1. c) Repair of fistula site d) Dartos flap coverage of the repair site

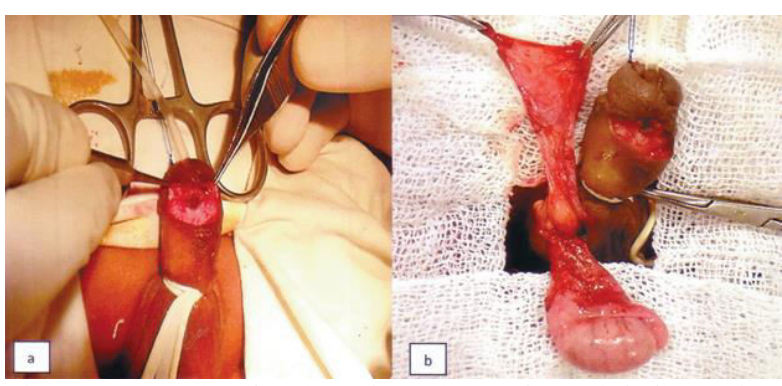

Figure 2. a) Fistula site after circumferential dissection b) Tunica vaginalis flap

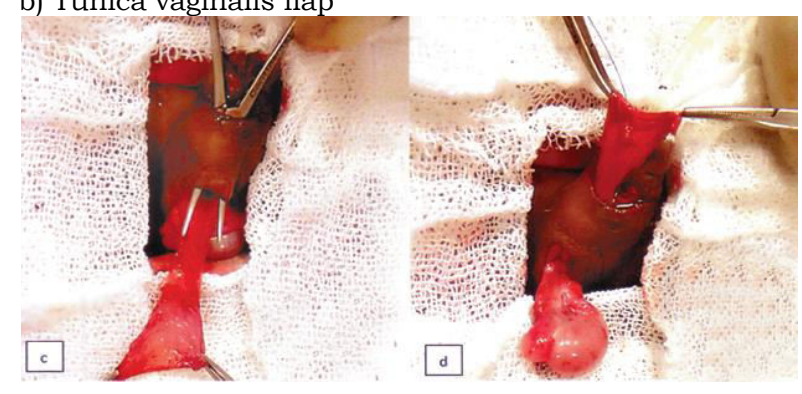

Figure 2. c) Flap was transferred to the repair site through a subdartos tunnel d) Tunica vaginalis flap on the repair site 
statistically significant differences in the terms of age $(p=0.83)$, location of fistula $(p=0.40)$, size of fistula $(\mathrm{p}=0.29)$.

\section{Table I}

Characterization of urethrocutaneous fistula after hypospadias surgery.

\begin{tabular}{lccc}
\hline & $\begin{array}{c}\text { Dartos flap } \\
\text { coverage } \\
(\mathrm{n}=36)\end{array}$ & $\begin{array}{c}\text { Tunica } \\
\text { vaginalis } \\
\text { coverage } \\
(\mathrm{n}=15)\end{array}$ & P value \\
\hline $\begin{array}{l}\text { Mean Age (Month) } \\
\text { Location of fistula }\end{array}$ & 82.05 & 79.60 & 0.83 \\
Coronal & 14 & 5 & \\
$\begin{array}{l}\text { Distal penile } \\
\text { Mid penile }\end{array}$ & 7 & 4 & 0.40 \\
Proximal penile & 9 & 5 & \\
Penoscrotal & 4 & 1 & \\
Fistula size & 2 & 0 & \\
Small (1 3mm) & 16 & 8 & 0.29 \\
$\begin{array}{l}\text { Large (3 6mm) } \\
\text { Mean operation time }\end{array}$ & 20 & 7 & \\
(Minute) & 97.67 & 107.20 & 0.003 \\
Recurrence & 7 & 0 & 0.066 \\
\hline
\end{tabular}

\section{Discussion}

UC fistula is still the striking complication of hypospadias repair. The reported incidence varies from 4 to $28 \% .^{5-7}$ Some tiny fistula may disappear spontaneously but most fistulas need surgical correction.8 UC fistula may recur after repair with reported proportions varying from $2.5 \%$ to $29 \% .9,10$

The coronal sulcus is a problematic site for healing in neourethral reconstruction as this site is relatively less vascular. The rate of fistula formation at the coronal sulcus was higher in our study $(37 \%)$. This has been reported in another studies by Elbakry (37\%) and Latifoglu et al. $(52 \%) .{ }^{11,12}$

Different techniques have been described for fistula closure. Simple closure of UC fistula has a high failure rate in comparison with other technique. Some studies have shown that multilayer closure with a second layer coverage in between the neourethra and the skin plays an important role in preventing UC fistula recurrence, regardless of the surgical repair method. Various vascularized flaps such as penile dartos fascia, scrotal dartos fascia, tunica vaginalis, de-epithelialized skin, and buck's fascia, can be used as the second layer. ${ }^{13-15}$

Using the dartos flap as second layer coverage, Shirazi et al. found $97.5 \%$ success rate. ${ }^{9}$ In another study, Mohamed et al. found 97.3\% success rate by using the dartos tissue as the intermediate layer. ${ }^{16}$ In this study, using similar tissue as second layer coverage, we observed $80.5 \%$ success rate.

A tunica vaginalis flap has been used for covering the neourethra after hypospadias surgery. It's use as second layer coverage after repair of UC fistula has been described by different authors with a variable recurrence rate. ${ }^{10,14,15}$ In the present study, no recurrence has been identified in any of the 15 patients who underwent fistula repair using the tunica vaginalis as second layer coverage. This result was similar with studies done by other authors. ${ }^{14,17,18}$

Usually the penile skin and dartos tissue is less, surrounding dartos and spongiosal tissue is fibrous, less elastic, less vascular and adherent with the penile skin, difficult to separate in cases where stage procedures done. On the other hand, tunica vaginalis is a highly vascular, elastic structure that can be easily harvested and reached to the coronal area without any tension. No patient of this study developed postoperative ventral chordee, probably due to its elastic properties with rich vascularity. There are some limitations of this study like small sample size and operation was done by different surgeons of different levels.

\section{Conclusion}

In spite of statistical insignificance, tunnelled tunica vaginalis as second layer coverage of fistula repair seems to be better than the dartos flap in preventing recurrence. Prospective raindomized clinical trials with large sample size are needed for definitive conclusion.

\section{References}

1. Eardley I, Whitaker RH. Surgery for hypospadias fistula. Br J Urol 1992; 69: 306-310

2. Redman JF. Results of undiverted simple closure of 51 urethrocutaneous fistulae in boys. Urology 1993; 41: 369-371

3. Ikuerowo SO, Bioku MJ, Omisanjo OA, Esho JO. Urethrocutaneous fistula complicating circumcision in children. Niger J Clin Pract 2014; 17: 145-148

4. Shirazi M, Noorafshan A, Serhan A. Effects of different suture materials used for the repair of hypospadias: A stereological study in a rat model. Urol Int 2012; 89: 395-401

5. Demirbilek S, Kanmaz T, Aydin G, Yucesan S. Outcomes of one stage technique for proximal hypospadias repair. Urology 2001; 58: 267-270

6. Uygur MC, Unal D, Tan MO, Germiyanoglu C, Erol D. Factors affecting outcome of one stage anterior hypospadias repair: Analysis of 422 cases. Pediatr Surg Int 2002; 18: 142-146 


\section{References}

7. Nuininga JE, De gier RPE, Verschuren R, Feitz FJ. Long term outcome of different types of 1-stage hypospadias repair. J Urol 2005; 174: 1544-1548

8. Waterman $\mathrm{BJ}$, Renschler $\mathrm{T}$, Cartwright $\mathrm{PC}$, Snow BW, de Vries CR. Variables in successful repair of urethrocutaneous fistula after hypospadias surgery. J Urol 2002; 168: 726-730

9. Shirazi M, Ariafar A, Babaei AH, Ashrafzadeh, Adib A. A simple method for closure of urethrocutaneous fistula after tubularized incised plate repair: preliminary results. Nephrourol Mon 2016; 8: e40371

10. Shankar KR, Losty PD, Hopper M, Wong L, Rickwood AMK Outc6me of hypospadias fistula repair. BJU International 2002; 89: 103-105

11. Elbakry A. Management of urethrocutaneous fistula after hypospadias repair. 10 years' experience. BJU International 2001; 88: 590-595

12. Latifoglu 0, Yavuzer R, Unal S, Cavusoglu T, Atabay K. Surgical treatment of urethral fistulae following hypospadias repair. Ann Plast Surg 2000; 44: 381386

13. Elsaket H, Habib EM. Systematic approach for the management of urethrocutaneous fistulae after hypospadias repair. Egypt J Plast Reconstr Surg 2009; 33: 285-290
14. Muruganandham K, Ansari MS, Dubey D, Mandhani A, Srivastava A, Kapoor R, Kumar A. Urethrocutaneous fistula after hypospadias repair: outcomes of three types of closure techniques. Pediatr Surg Int 2010; 26: 305-308

15. Sharma N, Bajpai M, Panda SS, Singh A. Tunica vaginalis flap cover in repair of recurrent proximal urethrocutaneous fistula: A final solution. Afr J Paediatr Surg 2013; 10: 311-314

16. Mohamed S, Mohamed N, Esmael T, Khaled S. A Simple procedure for management of Urethrocutaneous Fistula: Post hypospadias repair. Afr J Paediatr Surg 2010; 7: 124-128

17. Routh JC, Wolpert JJ, Reinberg Y. Tunneled tunica vaginalis flap is an effective technique for recurrent urethrocutaneous fistulas following tubularized incised plate urethroplasty. J Urol 2006; 176: 1578-1581

18. Landau EH, Gofrit ON, Meretyk S, Katz G, Golijanin $\mathrm{D}$, Shenfeld OZ, et al. Outcome analysis of tunica vaginalis flap for the correction of recurrent urethrocutaneous fistula in children. J Urol 2003; 170: 1596-1599 